\title{
LASERASI KANALIS LAKRIMALIS PADA LUKA ROBEK PALPEBRA DI RS. Dr. M. DJAMIL PADANG
}

\author{
Hendriati \\ Sub Bagian Rekonstruksi dan Okuloplastik Bagian Ilmu Kesehatan Mata \\ Fakultas Kedokteran Univeritas Andalas/RS. Dr. M. Djamil Padang \\ E-mail : irin970@yahoo.com
}

\begin{abstract}
Abstrak
Menentukan Epidemiologi laserasi kanalis lakrimalis pada luka robek palpebra di Rumah Sakit Dr. M. Djamil Padang.

Studi Retrospektif mengenai laserasi kanalis lakrimalis pada luka robek palpebra di Rumah Sakit Dr. M. Djamil dari bulan Juli 2006 - Juni 2009. Data dikumpulkan dari Rekam Medik.

Ada 29 orang pasien yang didiagnosa laserasi kanalis lakrimalis dari 229 kasus luka robek palpebra (12,66\%), 23 orang pasien $(79,31 \%)$ adalah laki-laki dan 6 orang lagi perempuan $(20,69 \%)$. Berdasarkan usia, laserasi kanalis lakrimalis paling banyak terjadi pada pasien berusia 41-50 tahun (27,58\%), paling sering terjadi di kanalis lakrimalis inferior, yaitu 18 kasus dari 29 (62.07\%). Berdasarkan lokasi kejadian, yang terbanyak adalah karena kecelakaan di jalan raya, yaitu sebanyak 16 dari 29 kasus (55.18\%). Berdasarkan penyebabnya, yang terbanyak adalah trauma tumpul. Sebanyak 23 dari 29 kasus tersebut dilakukan tindakan kanalisasi $(79,31 \%)$.

Trauma tumpul merupakan penyebab terbanyak laserasi kanalis lakrimalis, kanalikulus inferior lebih sering terjadi dari pada superior. Laki-laki lebih banyak dikenai dari pada perempuan, dan terbanyak di kelompok usia 41-50 tahun.

Kata kunci : laserasi kanalis lakrimalis, luka robek palpebra
\end{abstract}

\section{Abstract}

To determine the epidemiology of canalicular lacerations on eyelid injury at Dr. M. Djamil hospital.

A retrospective study of canalicular lacerations on eyelid injury in Dr. M. Djamil Hospital between July 2006 - June 2009. Data were colleted from medical record. There were 29 patient with diagnosis canalicular lacerations of 229 eyelid injury $(12.66 \%)$, twenty three patients $(79.31 \%)$ were males and 6 were females $(20.69 \%)$. Based on the age, canalicular lacerations was mostly found in the patient with aged 41-50 y o (27.58\%), canalicular lacerations was mostly present in lower canaliculi, with the frequency of 18 cases out of 29 cases $(62.07 \%)$. Based on place of injury, most of the patient get injury at high way, about 16 cases out of 29 cases $(55.18 \%)$. Based on source of injury, the most source of injury were blunt objects, canalization was the most common therapy 23 cases out of 29 cases $(79.31 \%)$. 
Blunt injury was the most common source of canalicular lacerations, the lower was more than upper. Male was more than Female, and mostly was found on age 41-50.

Key word : canalicular laceration, eyelid injury 


\section{Pendahuluan}

Laserasi palpebra sudah terjadi pada manusia sejak zaman dahulu. Tongkat runcing, sayatan pisau dan gigitan binatang mempunyai peranan besar menyebabkan terjadinya laserasi palpebra. Pada zaman moderen ini, trauma masih sering terjadi akibat kecelakaan lalu-lintas, gigitan binatang, perkelahian dan luka bakar. ${ }^{(1)}$

Laserasi palpebra dapat terjadi karena trauma tumpul atau disebabkan oleh benda tajam, gigitan binatang, perkelahian dan luka bakar. Laserasi tidak hanya melibatkan kulit, tapi dapat juga mengenai otot palpebra, margo palpebra dan sistim lakrimal. Laserasi pada bagian medial palpebra dapat menyebabkan robekan pada kanalis lakrimalis inferior, kanalis lakrimalis superior dan sakus lakrimalis. Hal ini menimbulkan gangguan sistim eksresi lakrimal yang meyebabkan epifora, sehingga memungkinkan berkembangnya abses di dalam sakus lakrimal dan terjadinya dakriosistitis. ${ }^{(2-4)}$

Pemeriksaan diagnostik yang tepat dan secara komperehensif perlu dilakukan dalam menegakan diagnosa, dalam hal ini termasuk pemeriksaan lapangan pandang, slit lamp, dan pemeriksaan funduskopi. Rontgen foto orbita atau CT scan harus dilakukan jika di duga suatu fraktur atau terdapatnya benda asing di dalam intra okuler atau intra orbita. ${ }^{(2)}$

Untuk meminimalisasi risiko timbulnya sikatrik dan epitelisasi pada luka dengan epifora, kanalisasi harus dilakukan paling lama dalam dua hari setelah luka. Idealnya stent inert, lembut dan lentur yang bertujuan untuk mengurangi iritasi okuler atau erosi jaringan dan cukup stabil ditempatkan pada perikanalikular untuk menurunkan reaksi inflamasi. ${ }^{(5)}$

Angka keberhasilan repair primer lebih tinggi jika dibandingkan dengan rekonstruksi skunder. Oleh karena itu, pada umumnya kesulitan dan kecendrungan timbulnya epifora berhubungan dengan rekonstruksi yang terlambat, dan banyak ahli bedah merekomendasikan untuk merepair semua kasus laserasi kanalikular. ${ }^{(2)}$

\section{Tujuan Penelitian}

Untuk mengetahui epidemiologi kanalisasi laserasi lakrimal di bagian mata RS. Dr. M. Djamil Padang selama periode 1 Juli 2006 hingga tanggal 31 Juni 2009.

\section{Metode dan Bahan Penelitin}

Merupakan sebuah penelitian deskriptif retrospektif dengan mengambil data dari Rekam Medik pasien yang didiagnosa Laserasi lakrimal Di bagian mata RS. Dr. M. Djamil Padang.

Penelitian ini menggunakan populasi semua penderita yang didiagnosa sebagai laserasi lakrimal pada bagian mata RS. Dr. M. Djamil Padang. Data yang dikumpulkan meliputi jenis kelamin, umur, tempat kejadian trauma, penyebab trauma dan terapi.

\section{Hasil Penelitian}

Selama periode 1 Juli 2006 hingga tanggal 31 Juni 2009 di bagian mata RS. M. Djamil Padang ditemukan 29 kasus laserasi lakrimal dari 227 kasus laserasi palpebra.

Tabel 1. Frekuensi laserasi lakrimal berdasarkan jenis kelamin

\begin{tabular}{lll}
\hline Jenis kelamin & Frekuensi & \% \\
\hline Laki-laki & 23 & 79.31 \\
Perempuan & 6 & 20.69 \\
\hline Jumlah & $\mathbf{2 9}$ & $\mathbf{1 0 0}$ \\
\hline
\end{tabular}

Pada tabel 1 telihat bahwa distribusi jenis kelamin yang banyak mengalami laserasi lakrimal adalah 
laki-laki yaitu 23 kasus dari 29 orang penderita $(79.31 \%)$.

Tabel 2. Frekuensi laserasi lakrimal berdasarkan umur

\begin{tabular}{lll}
\hline $\begin{array}{l}\text { Umur } \\
\text { (tahun) }\end{array}$ & Frekuensi & $\%$ \\
\hline $1-10$ & 5 & 17.24 \\
$11-20$ & 2 & 6.90 \\
$21-30$ & 7 & 24.14 \\
$31-40$ & 4 & 13.79 \\
$41-50$ & 8 & 27.58 \\
$51-60$ & 1 & 3.45 \\
$61-70$ & 1 & 3.45 \\
$71-80$ & 1 & 3.45 \\
\hline Jumlah & $\mathbf{2 9}$ & $\mathbf{1 0 0}$ \\
\hline
\end{tabular}

Pada tabel 2 terlihat bahwa distribusi umur yang banyak mengalami laserasi lakrimal adalah golongan umur 41-50 tahun (27.58\%) diikuti golongan umur 21 - 30 tahun $(24.14 \%)$ dan golongan umur $1-10(17.24 \%)$.

Tabel 3. Frekuensi laserasi lakrimal berdasarkan lokasi

\begin{tabular}{lll}
\hline Lokasi & Frekuensi & \% \\
\hline $\begin{array}{l}\text { Kanalis lakrimalis } \\
\text { inferior }\end{array}$ & 18 & 62.07 \\
$\begin{array}{l}\text { Kanalis lakrimalis } \\
\text { superior }\end{array}$ & 4 & 13.79 \\
$\begin{array}{l}\text { Kanalis lakrimalis } \\
\text { superior dan }\end{array}$ & 5 & 17.24 \\
$\begin{array}{l}\text { inferior } \\
\begin{array}{l}\text { Sakus lakrimalis } \\
\text { Duktus }\end{array}\end{array}$ & 1 & 3.45 \\
nasolakrimalis & 1 & 3.45 \\
\hline Jumlah & $\mathbf{2 9}$ & $\mathbf{1 0 0}$ \\
\hline
\end{tabular}

Terlihat pada tabel 3 bahwa lokasi yang terbanyak mengalami laserasi lakrimal terdapat pada kanalis lakrimalis inferior yaitu sebanyak 18 kasus $(62.07 \%)$ lalu kanalis lakrimalis superior dan inferior (17.24\%) dan kanalis lakrimalis superior (13.79\%).
Tabel 4. Frekuensi laserasi lakrimal berdasarkan tempat kejadian trauma

\begin{tabular}{lll}
\hline $\begin{array}{l}\text { Tempat } \\
\text { kejadian } \\
\text { trauma }\end{array}$ & $\begin{array}{l}\text { Fre- } \\
\text { kuensi }\end{array}$ & \% \\
\hline Rumah & 8 & 27.58 \\
$\begin{array}{l}\text { Jalan raya } \\
\begin{array}{l}\text { Rekreasi dan } \\
\text { olahraga }\end{array}\end{array}$ & 16 & 55.18 \\
$\begin{array}{l}\text { Industri atau } \\
\text { tempet kerja }\end{array}$ & 4 & 0 \\
$\begin{array}{l}\text { Bangunan } \\
\text { publik }\end{array}$ & - & 0 \\
Sekolah & 1 & 3.45 \\
\hline Jumlah & $\mathbf{2 9}$ & $\mathbf{1 0 0}$ \\
\hline
\end{tabular}

Pada tabel 4 terlihat tempat terjadinya trauma yang terbanyak adalah di jalan raya (55.18\%), di rumah $(27.58 \%)$ dan di tempat kerja $(13.79 \%)$.

Tabel 5. Frekuensi laserasi lakrimal berdasarkan penyebab trauma

\begin{tabular}{lll}
\hline $\begin{array}{l}\text { Penyebab } \\
\text { trauma }\end{array}$ & Frekuensi & \% \\
\hline $\begin{array}{l}\text { Benda } \\
\text { tumpul }\end{array}$ & 25 & 86.21 \\
Benda tajam & 4 & 13.79 \\
\hline Jumlah & $\mathbf{2 9}$ & $\mathbf{1 0 0}$ \\
\hline
\end{tabular}

Pada tabel 5 terlihat penyebab trauma yang terbanyak adalah disebabkan oleh trauma tumpul (86.21\%).

Tabel 6. Frekuensi laserasi lakrimal berdasarkan terapi bedah

\begin{tabular}{lll}
\hline Terapi & Frekuensi & \% \\
\hline Kanalisasi & 23 & 79.31 \\
Non & 6 & 20.69 \\
kanalisasi & & \\
\hline Jumlah & $\mathbf{2 9}$ & $\mathbf{1 0 0}$ \\
\hline
\end{tabular}




\section{Diskusi}

\section{Anatomi}

Sistim eksresi lakrimal terdiri dari pungtum lakrimalis, kanalis lakrimalis inferior dan superior, sakus lakrimalis, duktus nasolakrimalis dan hidung. Drainase sistim ekresi lakrimal masuk melalui pungtum inferior dan superior yang terletak pada margo bagian medial palpebra. Pungtum inferior terletak agak kelateral dibandingkan pungtum superior. ${ }^{(6-9)}$

Diameter pungtum lakrimal kurang lebih $0,3 \mathrm{~mm}$. Jarak pungtum inferior dari kantus medial $6,5 \mathrm{~mm}$ dan pungtum superior sekitar $6 \mathrm{~mm}$. Dari pungtum lakrimalis tear film diteruskan ke kanalis lakrimalis, sakus lakrimalis, duktus nasolakrimalis dan konka inferior. ${ }^{(6-8,10)}$

Panjang kanalis lakrimalis adalah sekitar 8-10 mm, sakus lakrimalis 12-15 mm dan duktus nasolakrimalis 12-18 mm. Untuk mencegah refluks tear film ke kanalis lakrimalis di sakus lakrimalis Rosenmuller. ${ }^{(6-8,11)}$

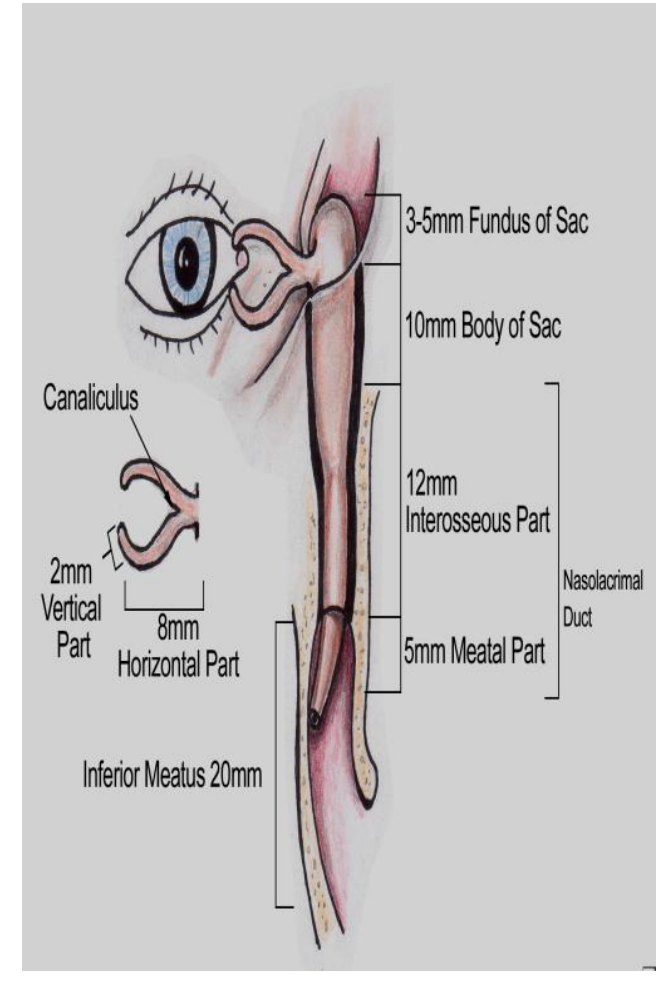

Gambar sistem lakrimal, Dikutip dari perpustakaan. $^{(12,13)}$

\section{Patofisiologi}

Laserasi kanalikular adalah robeknya saluran sistim lakrimalis. Laserasi sistim kanalis lakrimalis disebabkan oleh trauma langsung atau tidak langsung. Trauma langsung yang 
mengenai bagian lakrimal dari palpebra dapat disebabkan oleh trauma berat karena kaca, gantungan jas, pisau, gigitan anjing, cakaran kucing, kuku tangan atau benda tajam lainnya. Trauma tidak langsung disebabkan oleh trauma tumpul yang mengenai daerah sekitar mata seperti pukulan pada wajah, senjata tumpul atau benda tumpul. ${ }^{(2,14,15)}$

Laserasi pada kanalikuli selalu berhubungan dengan kerusakan pada daerah kantus medial, karena kanalikuli mulai dari pungtum sampai sudut kantus medial merupakan suatu struktur kompleks. Suatu hal yang tidak mungkin apabila dilakukan repair hanya pada kanalis lakrimalis saja, tanpa merepair struktur sekitarnya. Ruda paksa yang mengenai bola mata secara tiba-tiba sering menyebabkan penarikan pada bagian lateral dari kelopak mata atas maupun bawah. Hal ini dapat menyebabkan terjadinya laserasi dari kanalikuli. ${ }^{(8)}$ Sebagian besar kasus disini, tidak hanya mengenai kanalis lakrimalis tapi juga mengenai palpebra atau struktur sekitar mata, repair tidak hanya dilakukan pada kanalikular tapi juga daerah struktur sekitarnya.

\section{Epidemiologi}

Dari 5\% luka serius yang mengenai atau melibatkan palpebra dan sistem lakrimal, menyebabkan : ${ }^{(1)}$

- laserasi lakrimal $81 \%$

- laserasi periokular 70

- eritema palpebra $19 \%$

- obstruksi lakrimal $<1 \%$

- kelainan palpebra $<1 \%$

Pada penelitian ini, dari 229 kasus yang mengenai palpebra, 29 kasus melibatkan kanalikular (12.66\%).

Umur yang dikenai berkisar antara 0 90 tahun, dengan distribusi :

- usia $0-9$ tahun $23 \%$

- usia $10-19$ tahun $18 \%$

○ usia $\geq 60$ tahun $6 \%$
Menurut jenis kelamin, laki- laki sering dikenai dari pada perempuan (laki-laki $70 \%$ ). Menurut tempat terjadinya Trauma :

- di rumah $37 \%$

- di jalan raya $21 \%$

- tempat rekreasi dan olahraga $11 \%$

○ tempat industri $8 \%$

- bangunan umum $5 \%$

- di sekolah 3\%

Sedangkan menurut penyebab trauma, $28 \%$ disebabkan oleh trauma tumpul dan $16 \%$ disebabkan oleh trauma tajam. ${ }^{(1)}$

Di Amerika Serikat laserasi kanalikuli sering terjadi yang disebabkan luka pada sistem lakrimal. Laserasi kanalikuli lebih banyak mengenai kanalis lakrimalis inferior yaitu sekitar 50.75\% kasus, lebih sering mengenai laki-laki daripada wanita. Laserasi kanalikuli ini paling banyak mengenai usia muda dengan usia berkisar antara 18 - 30 tahun. $^{(6)}$ Sedangkan lan Q dan Wang ZJ melaporkan, ${ }^{(16)}$ dari 71 total pasien laserasi kanalikuli 44 orang mengenai laki-laki dan 27 orang perempuan, usia yang dikenai berkisar antara 16-55 tahun dengan usia ratarata 34.32 tahun. Pada penelitian ini, juga lebih sering mengenai anak lakilaki $(79.31 \%)$, sedangkan usia yang banyak dikenai adalah antara $41-50$ tahun yaitu $27.58 \%$.

Hoesin RG dan Witjaksana N juga melaporkan, lokasi kerusakan pada laserasi kanalikuli lebih sering terjadi pada kanalis lakrimalis inferior dibandingkan dengan bagian atas, dengan perbandingan 3-5:1, sedangkan kerusakan yang mengenai kedua kanalis lakrimalis superior dan inferior lebih jarang terjadi yaitu sekitar $16 \%$. Pada usia muda kerusakan yang terjadi dapat berupa laserasi yang disebabkan oleh karena benda tajam 
atau avulsi oleh benda tumpul, yang pada umumnya disebabkan karena kecelakaan lalu-lintas, perkelahian, kecelakaan pada saat olahraga dan gigitan binatang. ${ }^{(8)}$ Milin $^{(17)}$ melaporkan, dari 66 kasus laserasi palpebra, 24 kasus melibatkan sistim kanalikular, 13 (54.1\%) mengenai kanalis lakrimalis inferior dan $33.3 \%$ mengenai kanalis lakrimalis superior dan $12.5 \%$ mengena kanalis lakrimalis superior dan inferior. Di RSUP Dr. M. Djamil Padang dari Juli 2006 sampai dengan Juni 2009 sebagian besar kasus laserasi lakrimal juga mengenai kanalis lakrimalis inferior $(62.07 \%)$ diikuti oleh kanalis lakrimalis inferior - superior (17.24\%) dan kanalis lakrimalis superior (13.79\%). Sedangkan tempat kejadian trauma terbanyak adalah di jalan raya $(55.18 \%)$ dan penyebab terbanyak adalah karena benda tumpul (86.21\%).

\section{Diagnosis}

Diagnosis terjadinya laserasi pada kanalis lakrimalis dapat ditegakkan berdasarkan hal-hal sebagai berikut : ${ }^{(8)}$

1. Pada anamnesa terdapat adanya riwayat terjadinya trauma yang menyebabkan luka pada tepi kelopak mata bagian medial.

2. Dilakukan pemeriksaan oftalmologi untuk mengetahui apakah terjadi kerusakan didalam mata atau tidak. Pada anak-anak pemeriksaan ini mungkin memerlukan pembiusan secara umum. Bila terdapat luka penetrasi pada kelopak mata walaupun kecil, harus diwaspadai terjadi juga penetrasi pada bola mata.

3. Keadaan luka pada kelopak mata harus benar-benar diperhatikan karena ke- adaan tersebut akan menentukan jenis teknik operasi. Derajat luka serta ada tidaknya jaringan yang hilang harus diperkirakan luasnya. Apabila terdapat pergeseran dari pungtum lakrimalis kemungkinan besar terjadi laserasi pada kanalis lakrimalis.

4. Tes anel, apabila terjadi kebocoran pada cairan yang disuntikkan maka kemungkinan besar terjadi laserasi pada saluran lakrimalis.

5. Pemeriksaan penunjang seperti rontgen dan CT scan dapat dilakukan apabila di duga terdapat patah tulang orbita atau di duga terdapat benda asing di dalam rongga orbita.

6. Sebaiknya dilakukan dokumentasi terhadap luka yang terjadi serta kerusakan baik pada kelopak mata maupun bola mata.

\section{Penatalaksanaan}

Perbaikan luka pada kanalikuli harus dilakukan sesegera mungkin dalam waktu 48 jam. Mengingat sistim kanalikuli dimulai dari pungtum yang terletak pada kelopak mata atas dan bawah. Ada beberapa fakta yang harus diingat untuk menunjang keberhasilan operasi yaitu $:^{(1,7,18)}$

1. Sistim kanalikuli mempunyai bagian vertikal yang lebih pendek, sebagian besar berjalan horizontal dibagian medial kelopak mata pada permukaan konyungtiva.

2. Laserasi kanalikuli lebih banyak terjadi pada bagian medial.

3. Kanalikuli masuk ke sakus lakrimal diantara bagian ante- 
rior dan posterior dari tendon kantus medius.

4. Duktus nasolakrimalis masuk kedalam hidung bagian lateral melalui meatus inferior.

Prinsip tehnik operasi pada laserasi kanalis lakrimalis : $(1,19,20)$

1. Pada penderita yang kooperatif dan operator yang berpengalaman dapat dilakukan anastesi lokal.

2. Mengidentifikasi bagian proksimal kanalis yang terpotong adalah hal yang sulit dilakukan. Bila perlu dapat digunakan pigtail untuk mempermudah identifikasi.

3. Setelah bagian atas dan bawah kanalis yang terpotong dapat diidentifikasi, dimasukan probe dari selang silikon.

4. Bila selang silikon sudah masuk kedalam kanalis, dilakukan repair pada tendon kantus medial (apabila terjadi kerusakan pada tendon kantus medial)

5. Probe selang silikon yang terdapat didalam hidung tidak perlu dijahit, tetapi cukup dilakukan penyimpulan.

6. Bila selang silikon sudah pada tempatnya dan tendon kantus medial sudah pada posisinya maka dapat dilakukan penjahitan laserasi kelopak mata lapis demi lapis.

Stent yang dipasang pada kanalis yang luka bertujuan untuk mencegah striktura post operasi. Dengan memasang stent atau traksi, kanal dan jaringan lunak dapat kembali berada pada posisi anatominya. Pengangkatan stent ini dapat dilakukan dalam waktu 2 sampai 3 bulan.

\section{Kesimpulan}

1. Laserasi lakrimal di RS. M. Djamil Padang dari Juli 2006 sampai dengan Juni 2009 terbanyak mengenai laki-laki.

2. Usia terbanyak adalah $41-50$ tahun

3. Lokasi yang paling banyak dikenai adalah kanalis lakrimalis inferior.

4. Tempat kejadian tersering adalah di jalan raya.

5. Penyebab trauma tertinggi adalah karena benda tumpul

6. Terapi terbanyak adalah kanalisasi.

\section{KEPUSTAKAAN}

1. Tann TM and Long JA. Eyelid and Lacrimal Trauma. In: Ocular Trauma Principles and Practice. New York. 2002 : 371-381.

2. Protocol For Injuries to The Eye, di akses dari http://www.cour.ri.gov.com Akses terakhir 01/08/2009.

3. Daniel E and Buerger MD. Repair of Canalicular Laceration Can be Simplified IN : Ophthalmology Times July 11998.

4. Pitts J. Eyelid and Lacrimal Trauma In : Oculoplastic Surgery di akses dari http://www.oclb.com Akses terakhir 1/08/2009.

5. Ani S. Canalicular Tear Repair : Canula VS Silicone Stent In : Lacriml Lession 2008 : 321-322.

6. Jonatan J. The Lacrimal Systems. In : Atlas of Clinical and Surgical Orbital Anatomy. 1994. Ch 8 : 139147.

7. American Academy of Ophthalmolgy, BCSC. Orbit Eyelid and Lacrimal System Section 7. 
San Fransisco. 2008-2009: Ch14 : 265-270.

8. Emekli uffuk. Emergency repair of Lacrimal Canaliculus In SpringerLink - journal Article di akses dari http:// resources.metepress.com Akses terakhir 1/08/2009.

9. Kanski JJ. Eyelid Trauma In : Clinical Ophthalmology. London. 2004 : 659-661.

10. Khurana AK, Diseases of the Lacrimal Apparatus. In: Comprehensif Ophthalmology. Fourth Edition. New Delhi. 2007 : $365-365$.

11. Wobig Jl. Anatomi of Lacrimal System In : Ophthalmic Plastic and Reconstructive Surgery. San Fransisco. 1984 : 83-85.

12. Jebodhsingh K and Dan D. Aspects Pediatric Oculoplastics Trauma Floor Fracture and Canalicular Lacerations In: Ophthalmology Rounds. December 2008.

13. Parwar B. Nasolacrimal System Anatomy. di akses http://www.emedicine.com Akses terakhir 26/09/2009.

14. Locate MD. Canalicular Injury Epifora. In Eye Plastic di akses dari http://www.browlift.com Akses terakhir 1/08/2009.
15. Mawan LA. Laceration Canalicular di akses dari http://www.emedicine.com Akses terakhir 1/08/2009.

16. Lan Q and Wang ZJ. Therapieutic Effects of to Anastomoses of Lacrimal Passage on Canalicular In: Scien Direc - Chinese Journal of Traumatology.

17. Milind N, Naik Kelapure et al. Management of Canalicular Lacerations di akses dari http://www.find-health-articles.com Akses terakhir 1/08/2009.

18. Hyoung S, Cho, Hyun et al. A Simple New Method for Identifying the Proximal Cut end in Lower Canalicular Laceration. di akses dari http://www.find-healtharticles.com Akses terakhir 1/08/2009.

19. Lecuona K. Assessing and Managing Eye Injuries di akses dari http://www.cehjournal.com Akses terakhir 1/08/2009.

20. Martin L. Canalicular Ballon Fixation Stent di akses http://www.emedicine.com Akses terakhir 1/08/2009. 